\title{
Effect of EGR on Combustion and Emission Characteristics of Marine Dual Fuel Engines
}

\author{
Yu Hongliang ${ }^{1, a,{ }^{*}}$, Sun Peng ${ }^{1, b}$, Wu $\mathrm{Ji}^{2, \mathrm{c}}$, and Bian Jinlong ${ }^{3, \mathrm{~d}}$ \\ ${ }^{1}$ Navigation and Naval Architecture College, Dalian Ocean University, Dalian, China \\ ${ }^{2}$ Dalian Scientific Test and Control Technology Institute, Dalian, China \\ ${ }^{3}$ Dalian Shipbuilding industry Co., Ltd. Dalian, China \\ ayuhongliang19852@163.com, bsunpeng43793784@163.com, 'cmewuji@126.com, dbjl@163.com \\ *Corresponding author
}

Keywords: Combustion, Emission, EGR, Marine dual fuel engines.

\begin{abstract}
In this paper, in order to obtain performance of marine natural gas/diesel dual fuel engine on exhaust gas recirculation (EGR), the AVL-FIRE software had been adopted to numerical effect analyze of different EGR on combustive process and emission of the engine. The result shows that numerical simulation results are consistent with the tested pressure. The bursts pressure and temperature in-cylinder decrease $4.4 \%$ and $5.4 \%$ by EGR rate increase every $10 \%$. EGR rate increase make the temperature of the combustion area and the NO generation area in the cylinder decrease, the unburned equivalent ratio increase, the NO emission decrease.
\end{abstract}

\section{Introduction}

In order to reduce the NOx emission of the LNG / diesel dual fuel engine, part of the exhaust gas from the previous cycle of the engine operation is re-entered into the cylinder by using the exhaust gas recirculation (EGR), replacing part of the fresh air so that the intake charge is diluted and increased Gas heat capacity, which will reduce the combustion temperature in the cylinder. Reduced oxygen concentration, reduced combustion temperature, and reduced flame propagation rate will result in reduced NOx emissions, but a increase of $\mathrm{HC}$ emissions due to a decrease of oxygen concentration. With the increase in the amount of exhaust gas, the machine running cycle changes, combustion deterioration, integrated fuel consumption increased. In this paper, the effects on combustion and emission characteristics of diesel engine at different EGR rates of $0 \%, 10 \%$, $20 \%, 30 \%$ and $40 \%$ were studied in this paper.

Equations (1) is the EGR rate.

$$
\text { EGR rate }=m_{\text {ex. }} /\left(m_{\text {air }}+m_{\text {ex. g }}\right)
$$

Where, $\mathrm{m}_{\text {ex. }}$ is the amount of exhaust gas, $\mathrm{kg} / \mathrm{s}, \mathrm{m}_{\text {air }}$ is the fresh air flow entering, $\mathrm{kg} / \mathrm{s}$.

\section{Calculation model}

Modeling and meshing was by using AVL-FIRE software. In order to compare the differences of combustion progress by using different exhaust gas recirculations for marine DF engine, the calculations assumed that the initial state of the cylinder pressure and temperature in cylinder were uniform. Throughout the calculation process, the cylinder is closed system, heat transfer process was according to a given wall temperature boundary conditions calculations. The calculation was 
took into account the integral compression and power stroke, beginning with the scavenging port closed time and end with the exhaust valve open time, top dead center was $360^{\circ} \mathrm{CA}$.The technical specifications of the engine had given in Table.1.

Table1. Technical specifications of engine

\begin{tabular}{cc}
\hline Item & Parameter \\
\hline Bore $(\mathrm{mm})$ & 500 \\
Stroke $(\mathrm{mm})$ & 2000 \\
Rated rotate speed $(\mathrm{r} / \mathrm{min})$ & 108 \\
Rated power $(\mathrm{kW})$ & 7800 \\
Fuel system type & Direct Injection \\
Method of aspiration & Turbo-charging \\
Maximum cylinder pressure (MPa) & 16.17 \\
Charge air pressure (MPa) & 0.387 \\
Charge air temperature (K) & 305 \\
Coolant & water \\
\hline
\end{tabular}

\section{Model validation}

The results data is obtained by simulation of AVL FIRE software. To ensure the accuracy and reliability of the results of the calculation model, the data used for initial conditions of calculation model is obtained in the experiment. The comparison of cylinder pressure is shown in the Figure 1, between measure value and simulation value in the pure diesel mode and dual fuel mode.

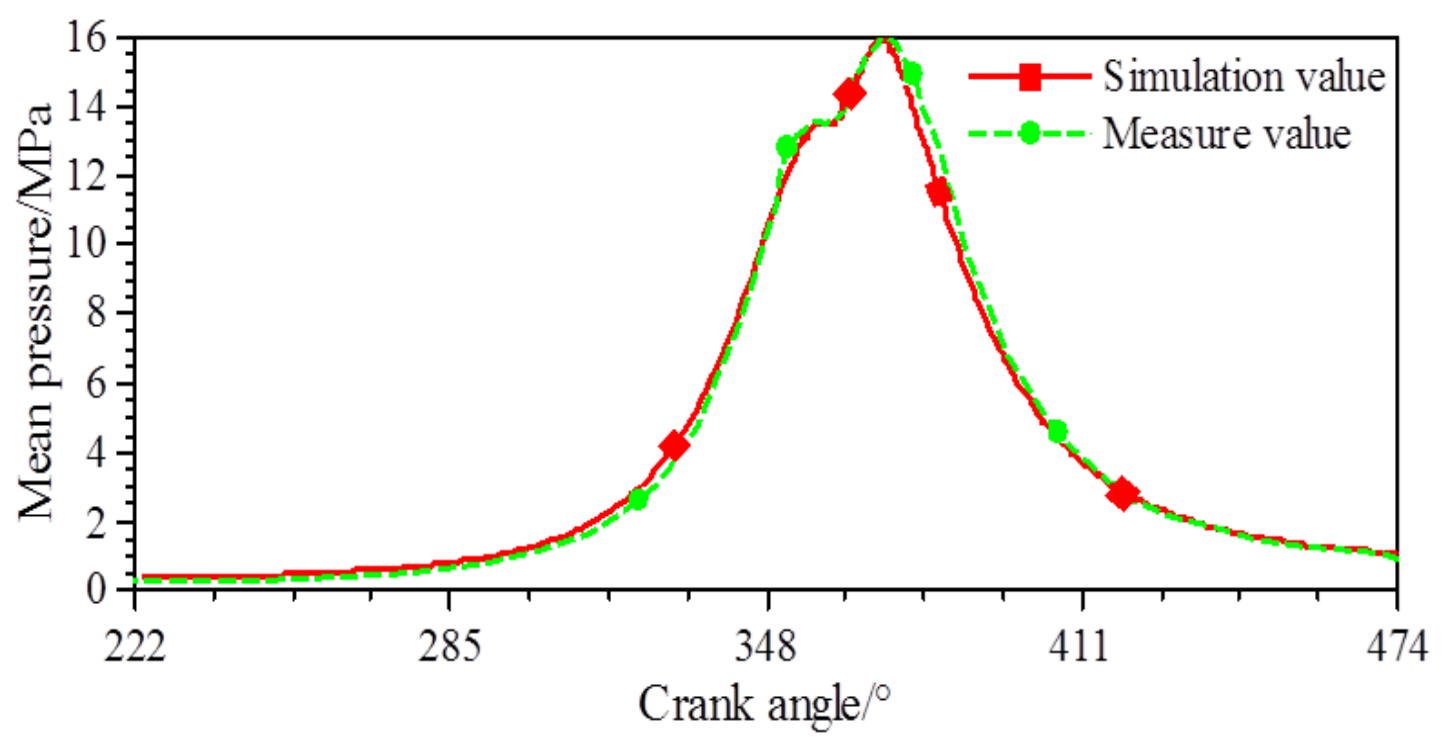

Fig 1 The comparison of cylinder pressure 


\section{Results and discussion}

\section{Combustion process analysis}

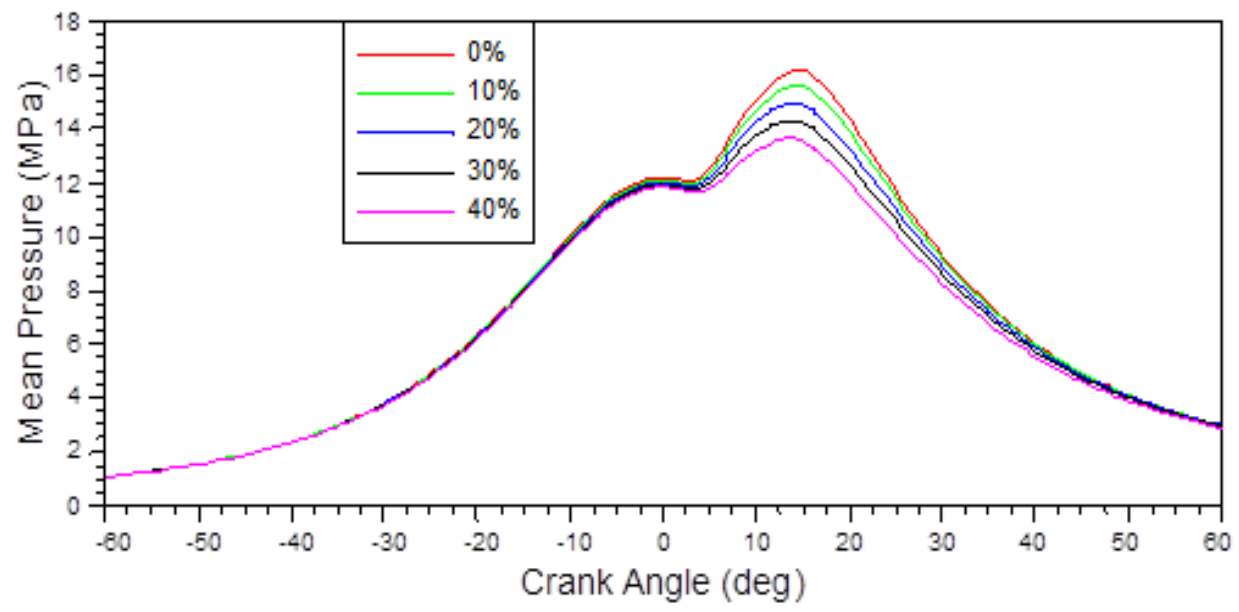

Fig. 2 Effect of EGR rate on pressure

As shown in Figure 2, with the increase of EGR rate, the pressure in the cylinder decreases gradually. The bursts pressure in-cylinder decrease an average of $4.4 \%$ with EGR rate increase every $10 \%$. This is because a lot of fresh air is replaced by carbon dioxide and water vapor, the combustion process is suppressed, resulting in the burst pressure drop.

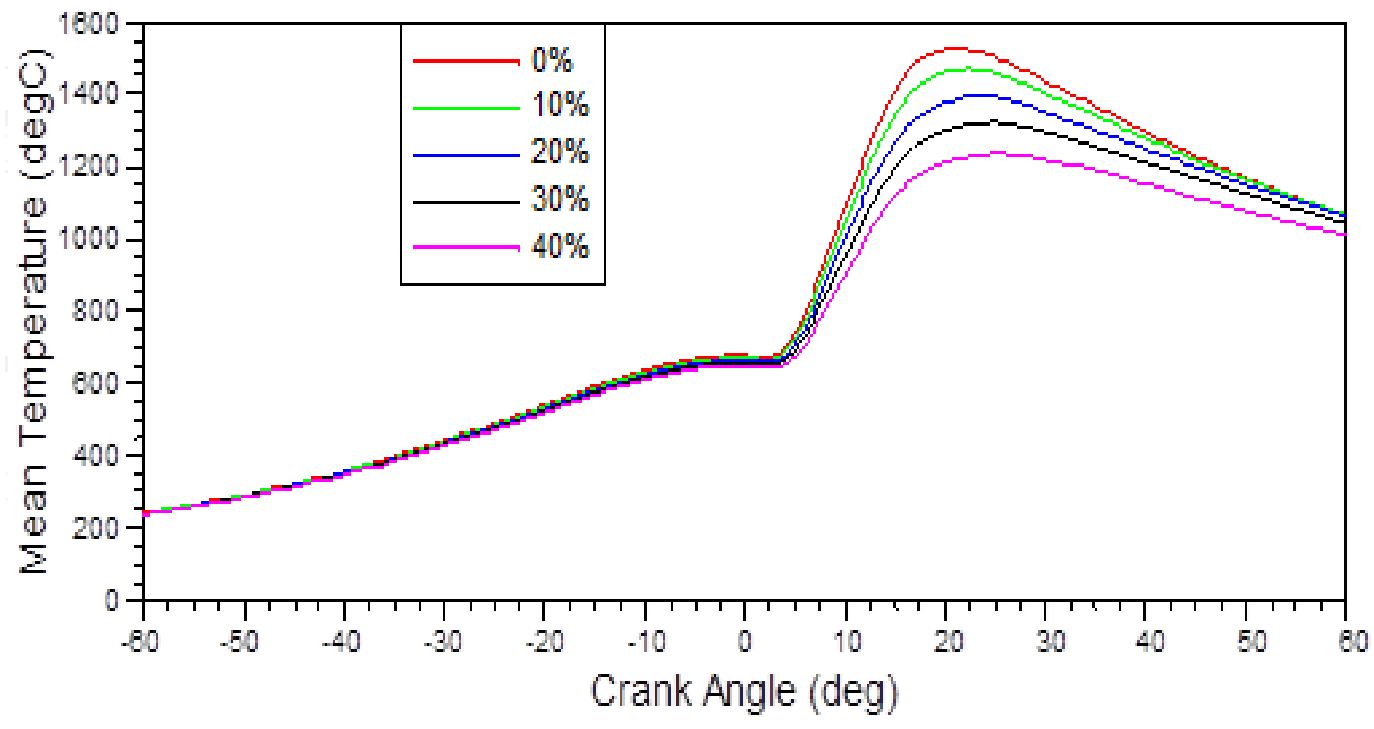

Fig.3 Effect of EGR rate on temperature

As shown in Figure 3, with the increase of EGR rate, the temperature in the cylinder decreases gradually. The temperature in-cylinder decrease an average of 5.4\% with EGR rate increase every $10 \%$. 
$10^{\circ} \mathrm{CA}$

ATDC
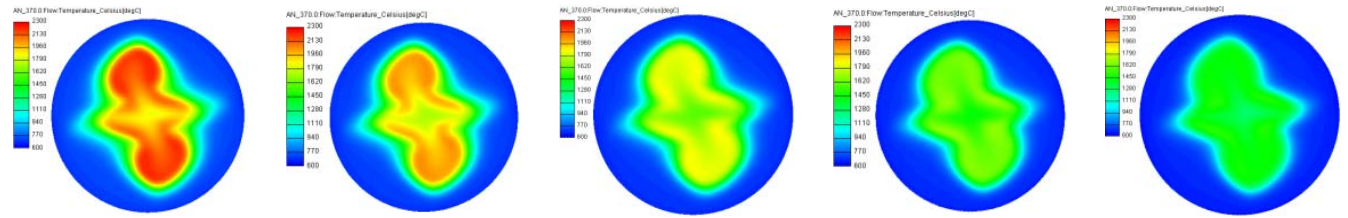

$15^{\circ} \mathrm{CA}$
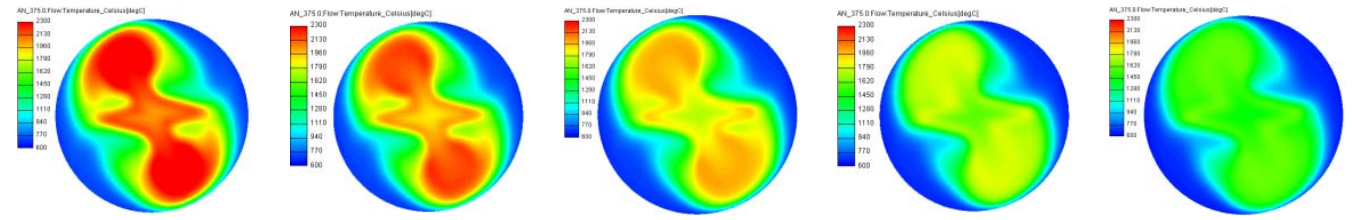

$20^{\circ} \mathrm{CA}$

ATDC
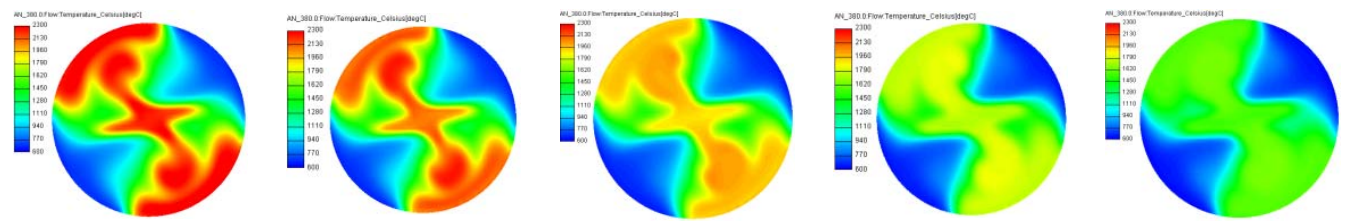

$\mathrm{EGR}=0 \%$

$\mathrm{EGR}=10 \%$

$\mathrm{EGR}=20 \%$

$\mathrm{EGR}=30 \%$

$\mathrm{EGR}=40 \%$

Fig.4 Effect of EGR rate on temperature of the combustion area

As shown in Figure 4, with the increase of EGR rate, the temperature of the combustion area in the cylinder gradually decreases. EGR rate increases, so that the concentration of oxygen in the combustible mixture in the cylinder is reduced, the premixed combustion rate in the cylinder is slow, resulting in the maximum temperature drop in the cylinder.

\section{Emissions analysis}

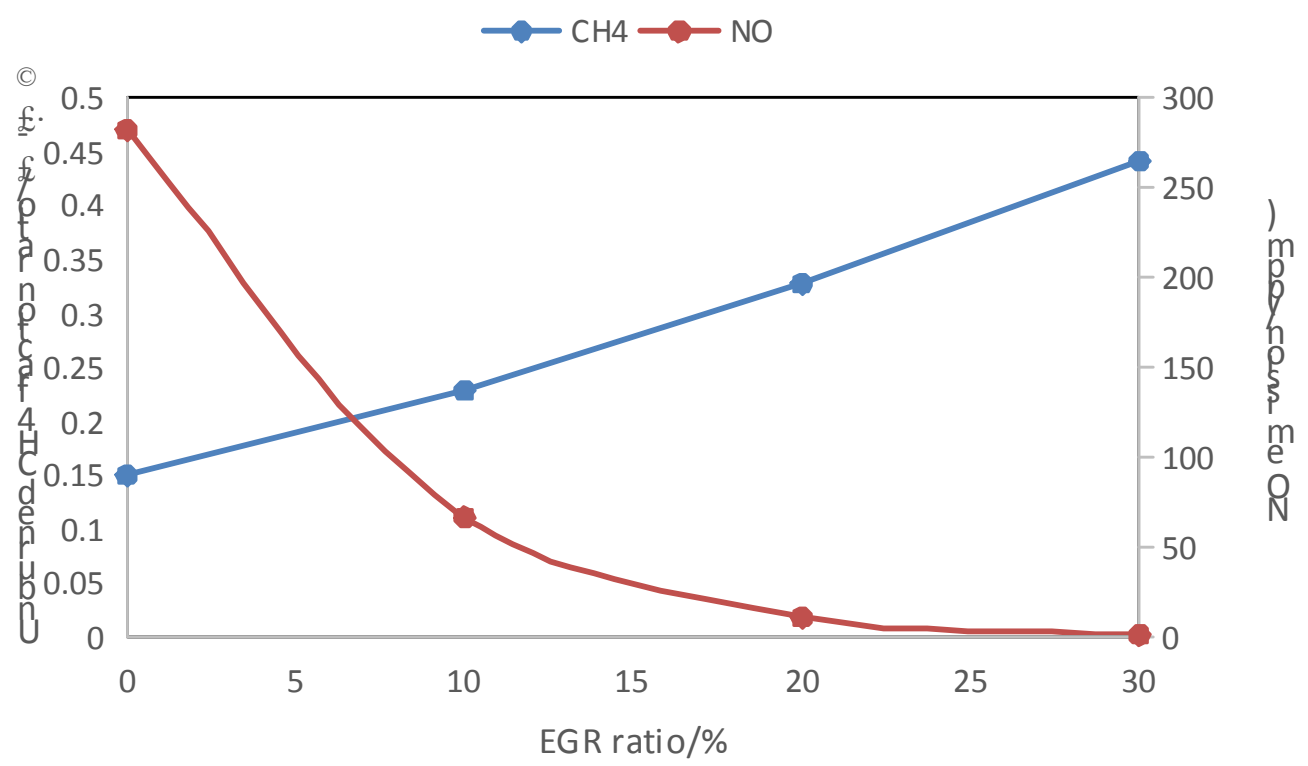

Fig.5 Effect of EGR rate on $\mathrm{CH}_{4}$ fraction and $\mathrm{NO}$ emission

As shown in Figure 5, with the increasing EGR rate, the unburned equivalent ratio increases and the NO emission decreases significantly. 


$10^{\circ}$
CA
AT
DC
$15^{\circ}$
CA
AT
DC
$20^{\circ}$
CA
AT
DC
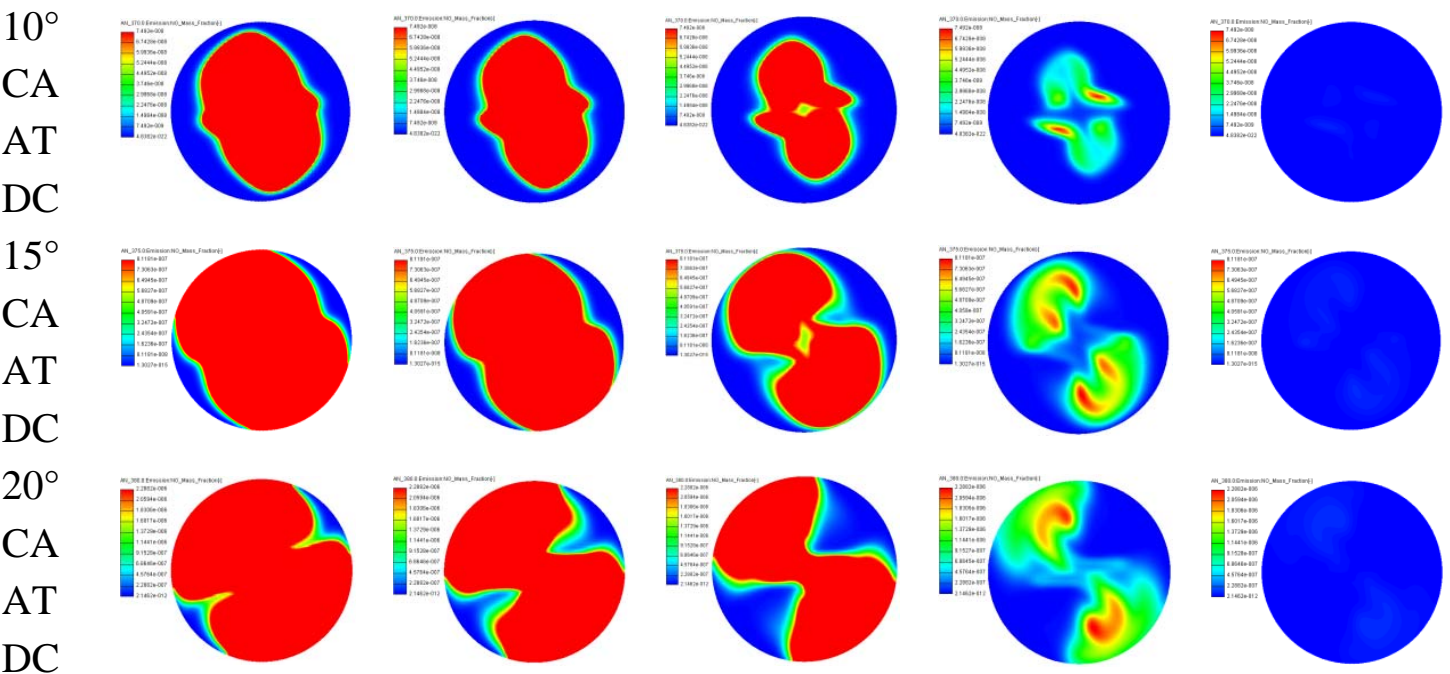

$\mathrm{EGR}=0 \%$

$\mathrm{EGR}=10 \%$

$\mathrm{EGR}=20 \%$

$\mathrm{EGR}=30 \%$

$\mathrm{EGR}=40 \%$

Fig.6 In-cylinder NO distribution

As shown in Figure 6, the generation area of NO in the cylinder decreases with the increase of EGR rate. High temperature and oxygen enrichment are two important conditions for NO generation. In a dual fuel engine, the use of EGR dilutes the intake air and increases the heat capacity of the mixture, so that the combustion temperature decreases and oxygen is reduced by carbon dioxide and water vapor. These two factors together inhibit the NO generation.
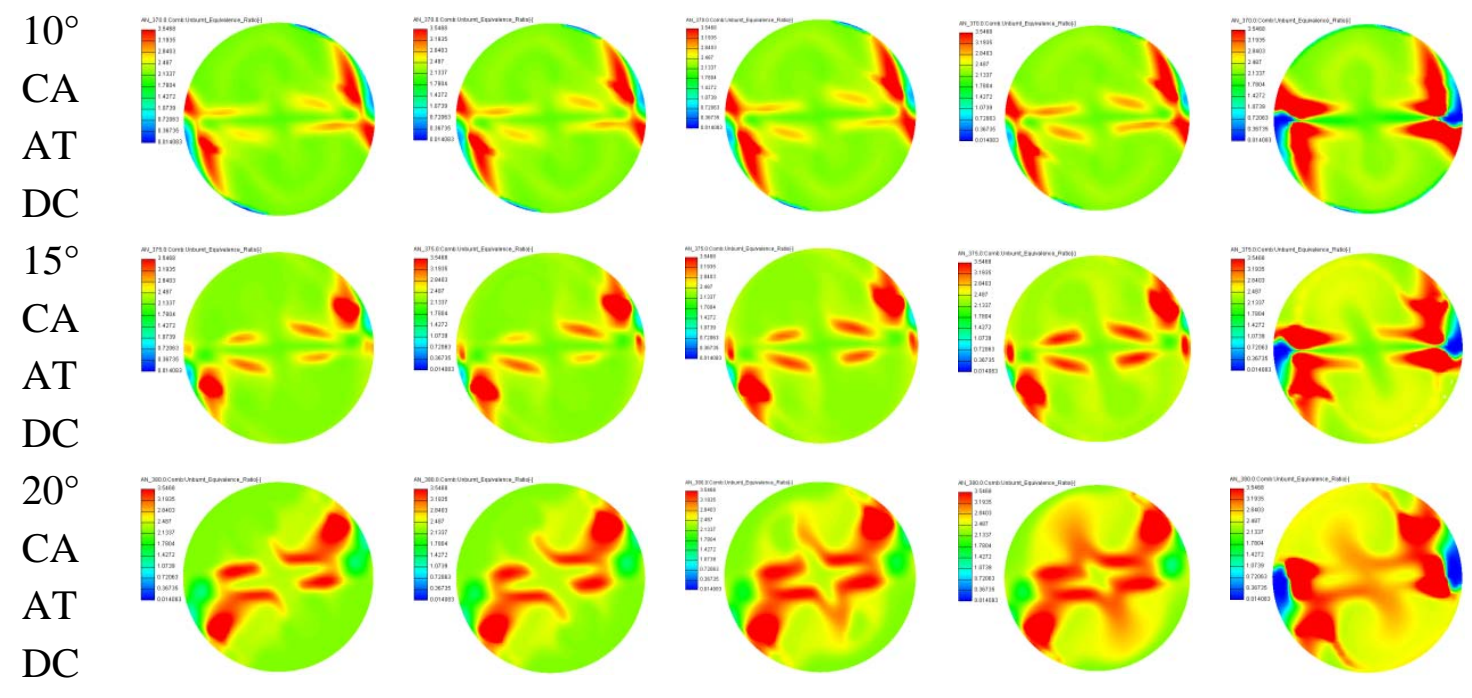

$$
\mathrm{EGR}=0 \%
$$

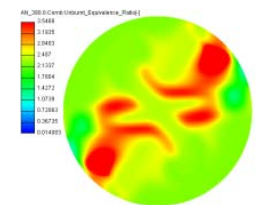

$\mathrm{EGR}=10 \%$

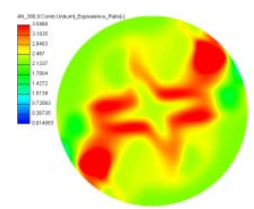

$\mathrm{EGR}=20 \%$

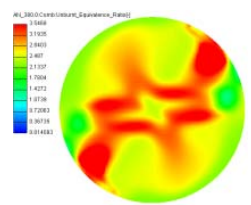

$\mathrm{EGR}=30 \%$

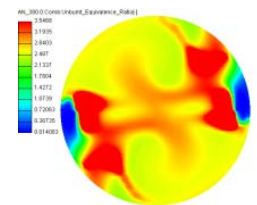

$\mathrm{EGR}=40 \%$

Fig.7 In-cylinder unburned $\mathrm{CH}_{4}$ distribution

As the EGR rate increases, the ratio of carbon dioxide and water vapor in the in-cylinder mixture increases, the oxygen concentration of the combustible mixture decreases, and the combustion process of the natural gas becomes slow, resulting in a large number of $\mathrm{CH}_{4}$ stagnation near the nozzles in Figure 7. 


\section{Summary}

With the increase of EGR rate, the pressure and temperature in the cylinder decreases gradually. The bursts pressure and temperature in-cylinder decrease $4.4 \%$ and $5.4 \%$ by EGR rate increase every $10 \%$.

with the increase of EGR rate, the temperature of the combustion area in the cylinder gradually decreases, the generation area of NO in the cylinder decreases, the unburned equivalent ratio increases, the NO emission decreases significantly.

\section{Acknowledgement}

This research was financially supported by scientific research projects from the education department of Liaoning Province (L201611).

\section{References}

[1] Abagnale C., Cameretti M.C., Simio L. De, Gambino M., Iannaccone S., \& Tuccillo R. , Numerical simulation and experimental test of dual fuel operated diesel engines, Applied Thermal Engineering. 65(2014) 403-417.

[2] Debabrata Barik, Murugan S, Simultaneous reduction of NOx and smoke in a dual fuel DI diesel engine,Energy Conversion and Management. 84(2014) 217-226.

[3] Sumit Roy, Ajoy Kumar Das, Rahul Banerjee, \& Probir Kumar Bose, A TMI based CNG dual-fuel approach to address the soot-NOx-BSFC trade-off characteristics of a CRDI assisted diesel engine-an EPA perspective, Journal of Natural Gas Science and Engineering. 20(2014) 221-240.

[4] Yu Hongliang, Duan Shulin \& Sun Peiting, Effects of LNG gasification temperature on combustion and emission characteristics of marine dual fuel engines, Journal of Propulsion Technology. 36(2015) 1369-1375.

[5] Yu Hongliang, Duan Shulin \& Sun Peiting, Effects of main/pilot timings on combustion and emission characteristics of marine dual fuel engines, Journal of Propulsion Technology. 37(2016) 1735-1741. 